\title{
The Gestation and Growth of the Periodic Table
}

\author{
David A. Johnson ${ }^{\mathrm{a}}$ and Alan F. Williams ${ }^{\star b}$
}

\begin{abstract}
The development of ideas of chemical periodicity from Lavoisier to Mendeleyev's first periodic table of 1869 is surveyed. Although his first periodic table contained a number of errors and weaknesses, his remarkable predictions of the properties of several then unknown elements, together with his capacity to adapt the table to new discoveries, slowly led to its general acceptance. The theory of atomic structure slowly developed to a point where it could rationalise the structure of the table which had, however, been established solely on the basis of experimental observations. Chemistry has played the central role, up to and including the final modification of Seaborg to introduce the actinides - although this had been foreseen by Alfred Werner! Finally we discuss the many physical forms in which the table has been presented.
\end{abstract}

Keywords: Actinides · Lanthanides · Mendeleyev · Periodic table
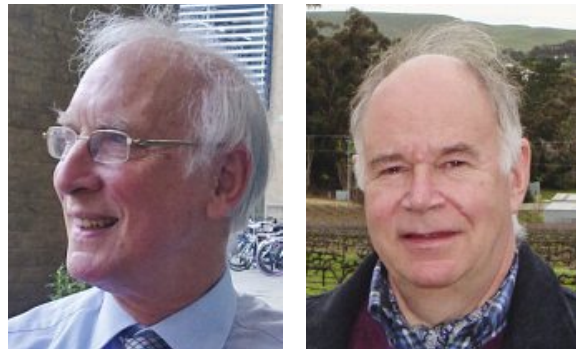

David Johnson (left) first met Alan Williams (right) in Cambridge fifty years ago when the former attempted to transmit some knowledge of inorganic chemistry to the other. Very soon the transmissions ceased to be oneway. They followed separate careers, David at the Open University (UK) and Alan at the University of Geneva, but have maintained a friendly contact ever since. The present manuscript is a result of these exchanges.

Few things symbolise chemistry better than the periodic table. It is found in almost every chemistry classroom or lecture theatre, and in almost all general chemistry text books. It shows in tabular form all the chemical elements, a veritable alphabet for the construction of substances or "the building blocks of Nature". [1] The periodic table satisfies one of the most basic instincts of the scientist, namely the discernment of a pattern in a mass of observations. On the one hand the systematic variation of properties on crossing or descending the table suggested an underlying structure for the chemical elements while on the other hand the periodic table acts as one of the most useful mnemonics in science. The simple localisation of an element in the periodic table is sufficient to allow a useful prediction of its properties: few chemists have not used arguments of the type "rubidium will be like potassium, but slightly larger". The close relationship between neighbours in the periodic table can stimulate the search for new compounds. The observation that organophosphines can act as ligands to transition metals leads one to think of similar behaviour by organoarsines or stibines. The discovery of a quadruple metal-metal bond in a rhenium acetato complex in 1964 stimulated the successful search for similar compounds formed by adjoining elements in the periodic table. ${ }^{[2]}$ As Mingos discusses in his contribution to this issue, ${ }^{[3]}$ the discovery of many xenon compounds was helped by knowledge of the isoelectronic compounds formed by iodine, the element next to xenon. The periodic table is thus a central element in chemical thought.

This edition of Chimia marks the $150^{\text {th }}$ anniversary of Mendeleyev's first version of his periodic table. Although the association of Mendeleyev with the periodic table is fully justified, his was only one of a series of contributions, and in this paper we will look at how chemical thought developed both before and after Mendeleyev's proposition. Although the general public delights in 'eureka' moments where the great scientist suddenly sees order in chaos, this is not always how science develops. In his excellent study of the history of the periodic table ${ }^{[4]}$ Eric Scerri argues that the development of the periodic table is a counterexample to Kuhn's theory of scientific revolution, ${ }^{[5]}$ and one can argue that the complete development of the periodic table took over a century, and that even now some questions remain open.

\section{Lavoisier and les corps simples}

Lavoisier and the French school introduced the notions of corps simples and corps composés. Although one would now translate these words as elements and compounds respectively, the term corps simple was initially distinct from an element, which had a significance whose origins lay in Greek philosophy. Lavoisier's definition was essentially empirical, but rigorous. A corps composé could in principle be broken down into corps simples; if this was not possible, the substance was itself a corps simple. In his 'Traité Elémentaire de Chimie' (1789) Lavoisier lists 33 corps simples, of which two (heat and light) would not now be regarded as elements. Twenty three of the others would now be classified as elements, while five (lime, magnesia, barytes, alumina and silica) would be regarded as compounds but contained elements not otherwise in Lavoisier's list. Lavoisier recognized that some substances then classified as corps simples might in the future be broken down to other corps simples. Three species were classified as radicals: muriatic (i.e. chlorine), fluoric and boracic. This approach set chemistry free from the ancient ideas of the four elements which formed a type of four-dimensional space from which matter was formed, and led to a modern classification 
of composition. Fig. 1 shows in red the elements which figured in Lavoisier's list; for those which had not been isolated as pure elements at that time, the date of isolation is given.

\section{Dalton Revives the Atomic Theory}

In contrast to the affluent Lavoisier, John Dalton was the son of a weaver in north-west England. As a Quaker he profited from the excellent instruction available in Quaker schools and became in turn a science teacher himself. He realized that the atomic theory proposed by Democritos could be adapted to Lavoisier's theory of corps simples. To each corps simple (or element), there corresponds a type of atom which cannot be transformed into another type of atom by a chemical reaction. Compounds may be represented by association of several atoms, with an integral number of each type of atom. Chemical reactions involved combination, separation or rearrangements of associations of atoms. Dalton also produced what might be regarded as the first structural representations of the combination of different atoms represented by symbols inside small circles although this was rapidly found to be impractical for printing press publication.

\section{The Search for Atomic Weights}

Dalton had introduced the atomic weight, the relative mass of one atom of an element compared to hydrogen, which was taken as one. To calculate the atomic weight from a weight percentage obtained from chemical analysis, one must know the stoichiometry. Dalton assumed for simplicity that most compounds would be binary, giving the formula $\mathrm{HO}$ for water and $\mathrm{HN}$ for ammonia, which led to atomic weights of 8 and 5 for oxygen and nitrogen, respectively. The determination of atomic weights of the elements would be a major concern of chemistry for the first half of the nineteenth century and was essential to the establishment of the periodic table. The atomic weight was one of the few parameters which could establish the existence of an element and distinguish it from others. More importantly it was a numerical parameter which could be compared with values for other elements; other such parameters were the density and the specific heat although these could only be used for solids and liquids.

Jöns Jakob Berzelius was one of the pioneers in this field, and he corrected Dalton's formulae for water and ammonia (and others) and replaced Dalton's esoteric symbols by the alphabetic symbols for elements we use today, adding the index to indicate the numbers of each element as in $\mathrm{H}_{2} \mathrm{O}$. He also used Avogadro's hypothesis of 1811 that equal volumes of gas at the same temperature and pressure contain the same number of molecules, but Avogadro's hypothesis was not fully exploited until the work of Stanislao Cannizzaro who published in 1858 his 'Sketch of a Course in Chemical Philosophy' ${ }^{[7]}$ which contained a consistent set of atomic weights based on a large volume of published work and used both Avogadro's hypothesis and Dulong and Petit's observation that the product of the specific heat of a solid element and its atomic weight was roughly constant. He advocated his views at the first international conference on chemistry, held in Karlsruhe in 1860, and one of his supporters distributed copies of his paper among the participants. His values for about 30 elements were widely accepted by the majority of chemists, not least by Lothar Meyer and Mendeleyev who were both present at the conference. Both recognized the atomic weight tables of Cannizzaro were essential to the development of their ideas although Lothar Meyer did not start developing his table for two years and Mendeleyev waited nearly nine years before publishing his.

In Switzerland atomic weights formed the central focus of the work of Jean-Charles Galissard de Marignac (1817-1894) who was professor of chemistry in Geneva between 1841 and $1878 .{ }^{[8]}$ In the course of his career he determined atomic weights for 28 elements and a brief study of some of his results shows some of the problems encountered by the chemists of the time. The methods available were essentially those of classical analysis. In the latter part of his career spectroscopic methods, developed by Bunsen and Kirchhoff in 1859, began to be used as
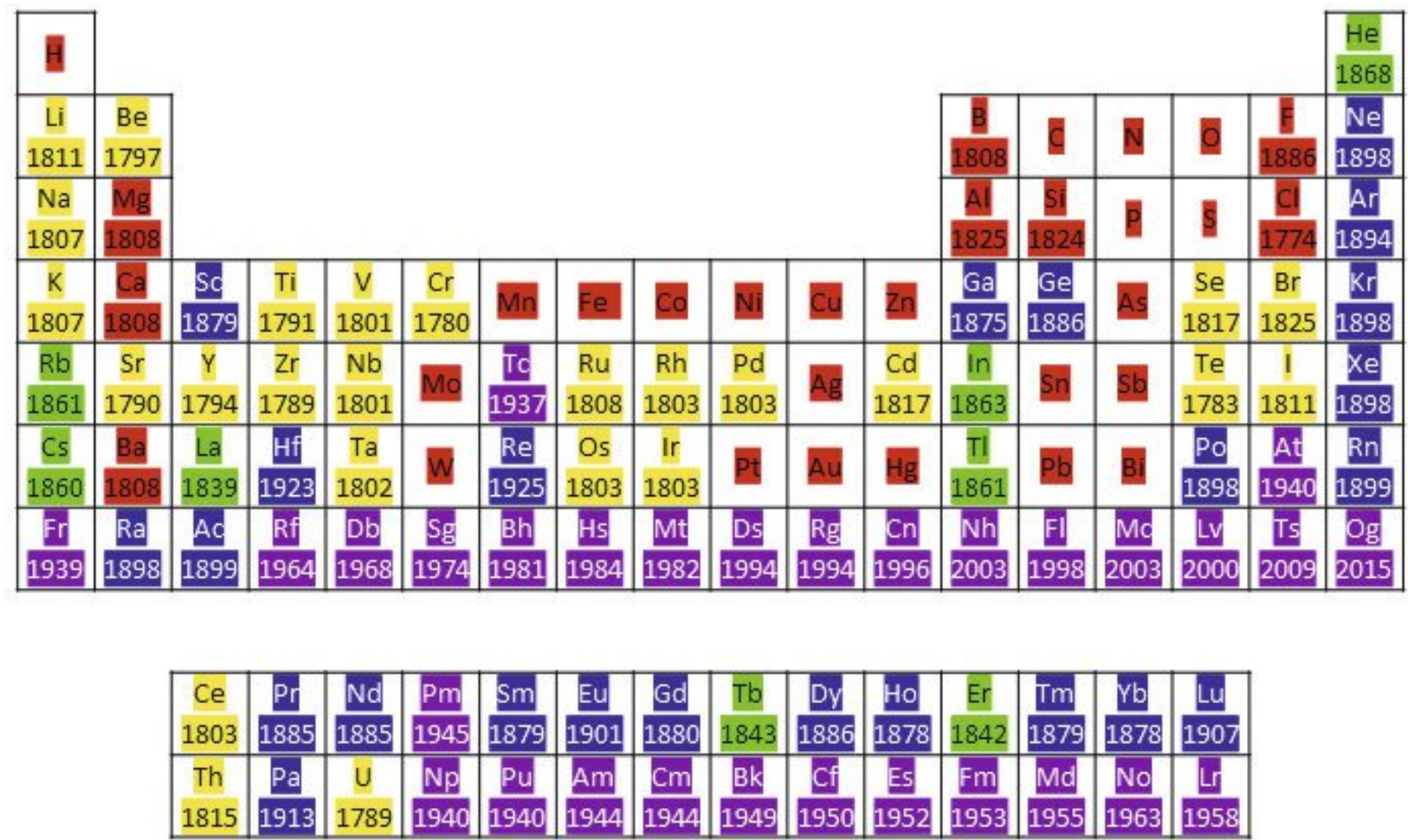

Fig. 1. The periodic table (at the time of writing). The elements are given together with the year of their discovery. The colour coding refers to the period of their discovery: red - cited by Lavoisier as a corps simple (the dates refer to the year of the isolation of the element if after 1789); yellow between Lavoisier and 1830; green - between 1831 and 1869; blue - from 1869 to 1930; violet - from 1930 to the present. Dates from Emsley. ${ }^{[1]}$ This presentation is that currently used by IUPAC. ${ }^{[6]}$ 
fingerprints for elements and helium was observed for the first time in solar radiation in 1868, but Marignac did not use them. Crystallography, on the other hand, was important because the isomorphism of two compounds could be used to argue that the formulae were identical. The atomic weight of silicon was obtained correctly only after Marignac showed that potassium fluorosilicate was isomorphous with the known potassium fluorostannate, and thus had the composition $\mathrm{K}_{2} \mathrm{SiF}_{6}$. Marignac also used fluoro-compounds to separate niobium and tantalum for first time and showed that the supposed element ilmenium was in fact a mixture of niobium and tantalum. Separation of elements was equally important for what is perhaps Marignac's best known work, on the rare earth elements, where he was the first to separate and name gadolinium and ytterbium, the only elements to be discovered in Switzerland.

\section{Looking for a System}

The period between 1789 and 1830 saw the discovery of more than twenty new elements (yellow in Fig. 1). As chemical similarities within families such as the halogens and the alkali metals became apparent, chemists naturally began to look for patterns. The Scottish physician William Prout was struck by the fact that many atomic weights were whole numbers (although in 1815 the quality of the data was not high). He proposed that the different elements were thus progressive associations of some basic unit. This idea has some appeal to us today, but was less popular at the time, especially when it was found that the atomic weights of elements such as copper and chlorine were nowhere near integral. Prout's hypothesis was progressively rejected even though the atomic weights of the elements were not randomly distributed. They clustered around integral values to a much greater extent than random probability would suggest. The next step involved the study of triads, a group of three elements with similar properties whose atomic weights were related in a way such that the second had an atomic weight close to the mean of the first and the third. Lithium, sodium and potassium are an example of such a triad. Several such triads were identified, but were not generalized to all the elements.

In writing his voluminous 'Handbuch der Chemie' in 1843, Leopold Gmelin adopted an organization of the elements which had many common points with the later periodic systems especially for what we would now call groups 1,2,15, 16 and 17 . The next crop of patterns only emerged after the conference of Karlsruhe. One of the first was proposed by the French geologist Alexandre Emile Béguyer de Chancourtois. His approach may be described simply as arranging the elements by order of increasing atomic weight and arranging the resulting one-dimensional structure into a helix such that similar elements lay above one another. He called this the telluric screw. His work was published but attracted little attention. We may see however the clear appearance of the notion of periodicity. The next step was from John Newlands who noticed a constant difference of 16 atomic weight units between sets of similar elements. A similar observation was made by another British chemist, William Odling. Newlands formulated his law of octaves which postulated that every eighth element had similar properties to the first (remember the noble gases were still unknown at this date). His work had a mixed reception, but he continued to publish refinements of his system.

The notion of periodicity was central to the work of Julius Lothar Meyer who produced a periodic table for the main group elements in his text book of chemistry in 1864, but had problems, as did everyone else, with the transition metals. He did however predict that unknown elements could be found to fill vacancies in his table. Lothar Meyer showed in a particularly striking way the periodic variation of atomic volume (Fig. 2), and also noted the regular variation of valency for the main group elements on crossing a period.

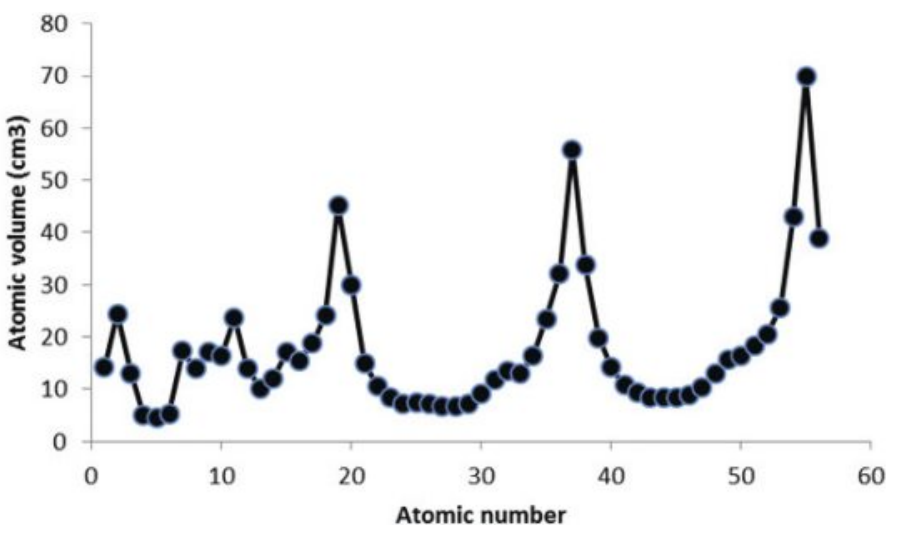

Fig. 2. The periodic variation of atomic volume, defined as the atomic weight divided by the density, first illustrated by Lothar Meyer. Densities are at $300 \mathrm{~K}$ except for gaseous elements where the density of the liquid at the boiling point has been used.

\section{Mendeleyev}



Fig. 3. Dmitri Ivanovich Mendeleyev. ${ }^{[9]}$

Dimitri Ivanovich Mendeleyev (Fig. 3) was born in Tobolsk, in western Siberia, in 1834, the last child of a large family. His father was a teacher who lost his sight and died while Mendeleyev was quite young. His mother took her 15 year old son to Moscow and then to St Petersburg where he was admitted to the Main Pedagogical Institute. He contracted tuberculosis after graduating in 1855 and moved to the Crimea, teaching science in Simferopol before returning to St Petersburg in 1857 where he started research. He visited Bunsen's laboratories in Heidelberg and while there attended the Karlsruhe conference. Returning to St Petersburg he published a well-received book on organic chemistry and in 1865 obtained his doctorate for work on alcohol-water mixtures. He was appointed professor in St Petersburg in 1867 and started teaching inorganic chemistry. It was this duty which led him to write his textbook 'The Principles of Chemistry' and it was while writing this that he began to think of the classification of the elements. Legend tells that on $17^{\text {th }}$ February 1869 , when he was supposed to be inspecting a 


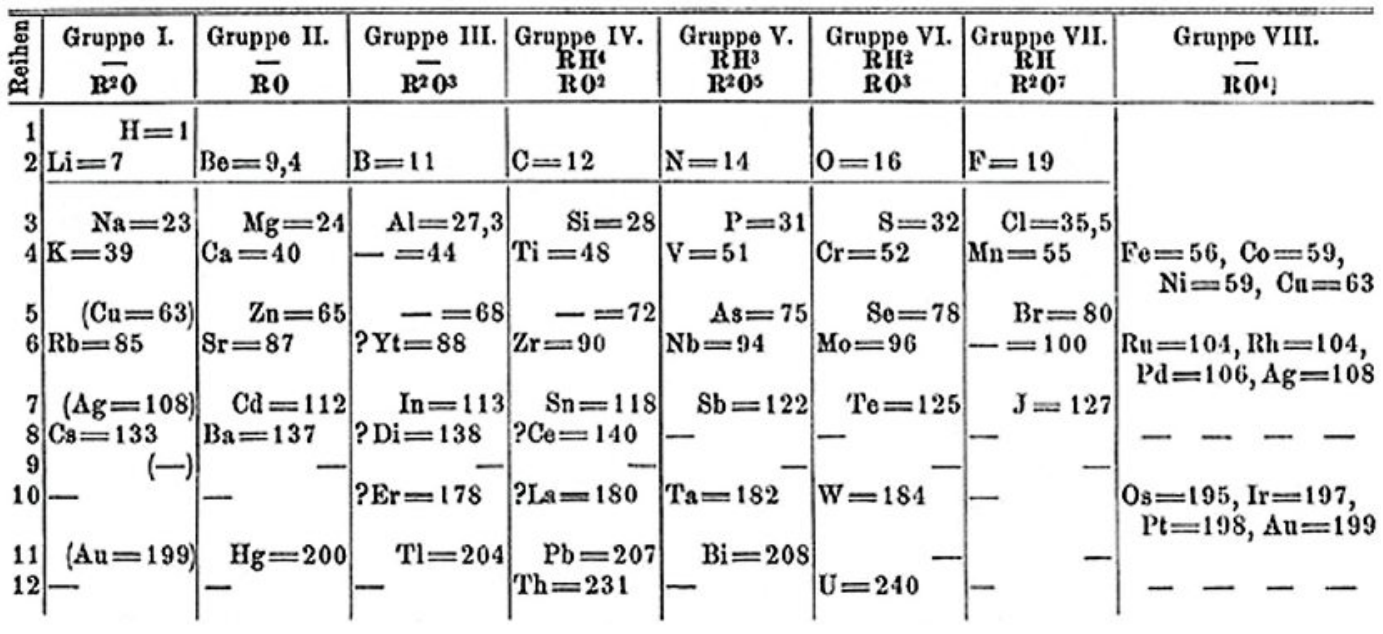

Fig. 4. A German version of Mendeleyev's 1871 periodic table which appeared in Annalen der Chemie und Pharmacie, 1871. cheese factory, he first conceived his periodic table. His first table was rotated by $90^{\circ}$ compared to modern tables with the period running vertically and the groups horizontally. A later version of 1871 is shown in Fig. 4.

Once he was convinced by his new table, Mendeleyev acted quickly: he had 200 copies of the table printed and distributed around Russia and Europe. In his first paper he lists eight points underlining the periodicity of properties, the regular variation of valencies and the similarities of properties of elements in the same group (e.g. the alkalis) or close together (e.g. Fe, Co and $\mathrm{Ni}$ in Group VIII). He also predicted the properties of new elements which appeared as gaps in his table.

We can now see that it is the maximum valencies that show the most regular variation, the highest normal oxides being compounds in which these valencies were more likely to be found. Their consequent importance is marked by the appearance of their formulae at the head of each group in Mendeleyev's table. With hindsight we may note that this emphasis on highest valency is a reflection of the fact that in compounds where it appears, all the valence electrons are generally used in bonding. It is the maximum valencies which justify the placing of $\mathrm{Mn}$ and $\mathrm{Cl}$ (or $\mathrm{Cr}$ and $\mathrm{S}$ ) in the same group since they have the same number of valence electrons even though they occupy different orbitals. If we look at the 1871 version, we may see the relationship between his groups and those as we know them today. He is apparently not quite sure about the coinage metals $(\mathrm{Cu}, \mathrm{Ag}$, and $\mathrm{Au})$ which appear both in group I and VIII, but the transition metals are fitted in nicely, even if one may find the sudden appearance of group VIII with three elements somewhat unaesthetic. The rare earths in series $8-10$ are obviously not satisfactory, with a large gap (of 45 Dalton in modern terminology) in atomic weights between $\mathrm{Ba}$ and $\mathrm{Ta}$, but only four of these elements were known at this time of which one (didymium) was actually a mixture of praseodymium and neodymium. Nevertheless, his table at least had space available to accommodate these mysterious elements. The rare earths would remain something of an enigma until the development of a useful theory of atomic structure as discussed by Piguet in another article in this edition.

Although Mendeleyev based his classification primarily on atomic weights he also considered chemical properties as important, leading him to invert the order of Te and I (he was not the first to do this) and to correct the atomic weight of beryllium, previously assigned to the aluminium group. We have discussed his use of valencies above. Writing his textbook had given Mendeleyev a very broad knowledge of inorganic chemistry which he used in developing his periodic table. This is illustrated in the predictions made for three elements corresponding to holes in his table: $e k a$-boron or scandium, No. 21, eka-aluminium or gallium, No. 31 and $e k a$-silicon or germanium, No. 32. He made seven pre- dictions concerning the atomic weight and chemical properties of scandium of which only one, that scandium would probably be discovered by spectroscopy, was incorrect. For gallium and germanium he made more predictions which were generally very close to the properties found with the exception of the anomalously low melting point of gallium. Full details are given by Scerri. ${ }^{[4]}$ All these predictions were made several years before the discovery of the elements, and may be regarded as a triumph of inductive reasoning.

Mendeleyev also made a number of incorrect predictions which are usually passed over, mainly to emphasize his contribution relative to other chemists. He made a number of suggestions to fill the gap in atomic weights between barium and tantalum, now filled by the rare earths. He equally postulated the existence of elements lighter than hydrogen which he thought to be possible candidates for the ether. Apart from his work on the periodic table he built up a high quality laboratory for chemical research in St Petersburg. His textbook 'The Principles of Chemistry' ran to eight editions and, from the fifth edition in 1889, was translated into German, English and French. He had many interests outside pure chemistry. Like Lavoisier he was interested in a scientific approach to farming and also worked on explosives. He was active in developing the petroleum industry in Russia and wrote extensively on economics. In 1890 he resigned his chair at the university, apparently for political reasons, but in 1893 returned to government service as director of the bureau of weights and measures, a position he held until his death from influenza a few days before his $73^{\text {rd }}$ birthday in 1907.

\section{Reaction to the Periodic Table}

Mendeleyev's table did not receive instant acclaim, even though he had made efforts to ensure that his ideas were widely discussed in Europe. The first of Mendeleyev's predicted elements to be discovered was gallium in 1875. Its discoverer, Emile Lecoq de Boisbaudran, apparently had no idea of Mendeleyev's predictions and was even rather suspicious when Mendeleyev wrote a note identifying gallium as his $e k a$-aluminium. Scandium, discovered by Nilson in 1879, ten years after Mendeleyev's first table, was only recognized as $e k a$-boron by the French chemist Pierre Clève. Shortly after this the British journal Chemical News serialized an English translation of Mendeleyev's 1871 paper on the periodic law. This provoked a dispute between Lothar Meyer and Mendeleyev concerning priority in the same journal which also published a criticism of the principle of periodicity itself by the Alsatian chemist Charles Adolphe Wurtz. Even as late as 1885 Marcelin Berthelot was criticizing the periodic table. More formal recognition came in 1882 when the Royal Society of London awarded the Davy medal jointly to Mendeleyev and Lothar Meyer. It awarded the same medal five years later to John 
Newlands whose publications predated the others. The discovery of germanium by Winkler in 1886 was initially interpreted by Winkler as $e k a$-stibium, an element between antimony and bismuth with an atomic weight in the range now filled by the lanthanides. Mendeleyev favoured $e k a$-cadmium, but von Richter noted that it fitted the predictions for $e k a$-silicon and this was supported by Lothar Meyer.

\section{Adapting to New Discoveries}

The end of the nineteenth century saw a number of discoveries which were all assimilated into the periodic table. The number of lanthanides grew steadily, filling up the gap in atomic weights between barium and tantalum. A more serious problem appeared to be the discovery of argon by Rayleigh and Ramsay. ${ }^{[10]}$ Mendeleyev was very suspicious of this, as indeed were many other scientists, until Ramsay's isolation of neon, krypton and xenon justified the creation of a whole new zero-valent group. Mendeleyev denoted it Group 0 and, in the final edition of his book, fitted it into his table by adding a new column to the left in Fig. 4,[11] thus preserving the regular change in maximum valency. The group would soon be completed by radon. The discovery of radioactivity raised some new problems. Clearly Dalton's doctrine of the indivisible atom could no longer be maintained, but worse was to come. Study of decay pathways led to strange patterns such as the decomposition of thorium to radium which then decomposed to another product which was chemically identical to thorium. This seemed nonsensical until Soddy proposed in 1910 that the different forms might have different mass but identical chemistry, and proposed the term isotope indicating that they occupied the same place in the periodic table. J.J. Thompson in Cambridge began to study "positive rays' (in fact cations produced in a discharge tube) and working with Francis Aston in 1913 showed that there were two types of cation produced by a sample of neon. Aston returned to this problem after the first World War and by 1919 had constructed his first mass spectrometer which established beyond doubt the existence of isotopes of stable atoms. At first sight this appeared to be a triumph for Prout's hypothesis since the isotopes had masses corresponding to exact numbers of protons, with chlorine showing $75 \%$ of isotope ${ }^{35} \mathrm{Cl}$ and $25 \%$ of ${ }^{37} \mathrm{Cl}$. Aston rapidly improved the mass resolution of his apparatus to reveal slight differences from the exact numbers which arose from the binding energy of nuclei.

\section{The Theory of Atomic Structure}

The progress in the understanding of atomic structure raised hopes of finding a theory explaining the structure of the periodic table. Rutherford had established in 1910 that the atom consisted of a small, positively charged nucleus surrounded by electrons. As early as 1913, Niels Bohr used periodic chemical properties to construct possible shell configurations for elements 1-24 in which his choice of the number of outer electrons was dictated by the preferred valency. ${ }_{[12]}$ He thus assumed that the interactions between different atoms which characterize the chemical bond are controlled by these electrons. They may be removed to form cations or extra electrons may be added to give anions. The isolation of the nucleus from chemistry explains why isotopes, which have the same number of external electrons and the same nuclear charge, Z, but different nuclear masses, will show almost identical chemical properties. It is worth noting that at this stage, the neutron had not been thought of, and the nucleus was assumed to be composed of protons and electrons bound in some way, with an excess of protons to give the positive charge.

$Z$ is now associated with the atomic number, but it should be recalled that this latter was initially merely a serial number in the periodic system. It was the Dutch physicist Anton van den Broek who first suggested that this serial number was equal to the positive charge of the nucleus. This idea was developed in the brief career of Henry Moseley who studied the frequencies of $\mathrm{X}$-rays emitted on electron bombardment by different elements, and showed that the frequency was proportional to $(Z-1)^{2}$. His first paper reported results for 14 elements and his second for 30 more. This method provided a test for the many substances proposed as missing elements in the periodic table, showing several to be spurious. Its power was shown when Georges Urbain, a distinguished French lanthanide chemist, submitted a sample to Moseley who not only determined rapidly which lanthanides were present, but even gave quantitative estimates which agreed with those obtained by painstaking chemical analysis. The identity of nuclear charge and atomic number was fully confirmed after the war by Chadwick in Cambridge.

Bohr's atomic theory established the importance of quantization and gave insight into the origin of atomic spectra. He recognized the shell structure of the atom and the importance of the external electrons, and the periodicity in the number of external electrons for example in the alkali metals. In his Nobel Prize lecture of $1922,{ }^{[13]}$ Bohr discusses the periodic table but his ideas concerning the occupation of orbits are difficult to follow. It was only after the introduction of the exclusion principle by Pauli in 1925 and the development of wave mechanics in 1926 that the modern orbital model of the atom was developed, the term atomic orbital being introduced in 1932 by Mulliken. As discussed by Mingos elsewhere in this issue, Kossel and Lewis recognized before 1920 the importance of electron configuration and the stability of a noble gas configuration. Lewis developed the first electronic model of chemical bonding, which has proven remarkably resilient since then, and links the electronic structure to the observed valencies of the elements. It is worth noting however that, although the periodic table may be rationalized in terms of atomic orbitals, it cannot be deduced $a b$ initio from quantum mechanics.

\section{The Nuclear Age}

By 1930 when the theory of atomic structure had finally rationalized the periodic table, nine elements had been found to complete the table created by Mendeleyev sixty years earlier, not counting the noble gases. The only missing elements were 43 (technetium, although it now seems probable that this element had been observed in nature), 61 (promethium which X-ray spectra and theory suggested to be missing), 85 (astatine) and 87 (francium). Up to then the best way to find a new element was to make friends with a mineralogist, and to be prepared to carry out a long and tedious separation procedure. Nuclear physicists had by now learnt to initiate nuclear reactions by bombardment with elementary particles, and this would henceforth be the approved method to discover elements, helped by the development of suitable sources such as the cyclotron, and, above all, the nuclear reactor.

The first artificial element to be isolated was technetium, found by Segrè and Perrier in 1937 in a molybdenum target which had been irradiated in E.O. Lawrence's cyclotron. In the next ten years seven more elements were synthesized, mostly in the actinide series. Up till then thorium and uranium had usually been placed in groups 4 and 6 on the basis of their typical oxidation states of +IV and +VI respectively, and the newly discovered protactinium also showed the expected $+\mathrm{V}$ oxidation state. However, as more transuranium elements were produced, Seaborg pointed out that from americium and curium onwards they resembled the rare earth elements more than the transition metals and proposed that this series of actinides corresponded in fact to the filling of the $5 \mathrm{f}$ shell. ${ }^{[14]}$ This was the last major modification of the periodic table, and was, as usual, based on chemical evidence not physical theory. The hypothesis was widely accepted although periodic tables with thorium and uranium in the transition metals could still be found in text books as late as 1960 . The story of the superheavy elements is given by Türler later in this edition. 
It is interesting to note that the rate of discovery of new elements has only dropped slightly during the 150 years since Mendeleyev's first table, with 14 new elements reported in the last 50 years. The half-lives of the newest elements are too short for a deep investigation of their chemistry to be foreseeable, but there is some hope from nuclear theory that elements around $Z=126$ might be rather more stable. This raises the intriguing possibility of the appearance of $5 \mathrm{~g}$ orbitals in chemistry. Going further, atoms with very high $Z$ will have 1 s electrons approaching the speed of light, and relativistic effects will become very important, and the stability of the orbital-based atom may be in question.

\section{Theme and Variations}

If there is unanimity about the existence of the periodic table, there is considerable debate about the form which it should take. The two tables in Figs 1 and 4 may both be described as periodic tables, but are clearly quite different. How is a periodic table constructed? If we imagine the elements arranged in order of increasing atomic number (Mendeleyev would have used atomic weight) on a strip, the table is produced by cutting the strip at intervals and aligning the fragments of strip so that elements on different fragments with similar properties lie next to each other. Thus Fig. 4 involves cutting the strip after helium, fluorine and chlorine. Iron, cobalt and nickel form a separate triad before copper and zinc are aligned with potassium and calcium, and so on. Carrying on this process leads to Fig. 4, often referred to as the short form of the periodic table. Although this was widely used, the similarities between manganese and chlorine are somewhat tenuous apart from the criterion of maximum valence. This point was addressed by assigning the elements to two subgroups A and B indicated by left or right justification in Fig. 4. This is a cumbersome system, not helped by the decision of American and European chemists to use opposite nomenclatures for the sub groups A and B. Mendeleyev produced another representation in 1879 where the cuts were made after the halogens (or after the noble gases once they were discovered) giving periods of 18 elements. This gives something close to Fig. 1 if one ignores for the moment the lanthanides and actinides, and has been widely used in textbooks in recent years, with the columns numbered with Arabic numerals rather than Roman. It is often referred to as the medium length table.

The discovery of the lanthanides gradually filled the gap in atomic weights between barium and tantalum, but left the question of how to include them in the table. Their remarkable chemical similarity clearly differenced them from the major changes observed on traversing a period in the rest of the periodic table. It was not possible to integrate them into a short table such as Fig. 4. Until 1940 when actinide elements needed to be included, the standard practice was to include the lanthanide series as a sort of footnote to the main table, indicating its place as between lanthanum (in the scandium - yttrium group) and hafnium. This is the thinking behind the table in Fig. 1. However relegating some 30 elements to a footnote is hardly satisfactory, especially if one is a lanthanide chemist. An early attempt to deal with this is due to Julius Thomsen ${ }^{[15]}$ who was professor of chemistry in Copenhagen when Niels Bohr was a student.

An updated version of Thomsen's table is shown in Fig. 5. It has atomic number increasing vertically down a column and involves no gaps between neighbouring elements within a period or awkward footnotes. Thomsen's table influenced Bohr who used an updated version of his own in his 1922 Nobel lecture on atomic structure. The relationships within a group appear either as horizontal lines (e.g. $\mathrm{Li}-\mathrm{Na}$ ) or diagonals $(\mathrm{Na}-\mathrm{K})$. It also illustrates one problem which has been the subject of some controversy. Clearly $\mathrm{Sr}$ is linked to $\mathrm{Ba}$, but does $\mathrm{Y}$ link to $\mathrm{La}$ and then Ac or to Lu and then Lr? Either way there will be a block of $2 \times 14$ elements with no affiliation to the left, and these are the lanthanides and actinides. It is now quite well established from the

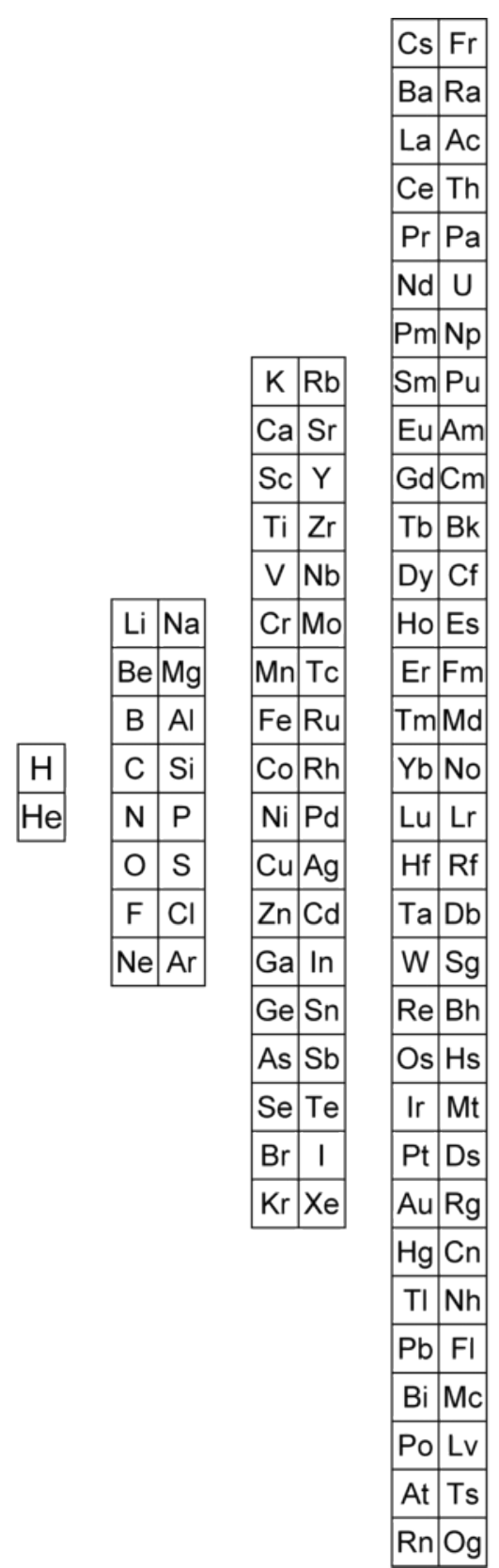

Fig. 5. The Thomsen representation of the periodic table updated to include all known elements.

study of ionization energies that Lu and Lr follow Sc and Y better than La and Ac. ${ }^{[16]}$ The IUPAC table in Fig. 1 is something of a compromise, removing two elements from group 3 to give a $15 \times 2$ element block which on present understanding would contain 14 lanthanides, 14 actinides and two transition metals.

Alfred Werner published in 1905 a periodic table ${ }^{[17]}$ which included all the lanthanides then known (Fig. 6) but which used the conventional arrangement with the periods horizontal and may be referred to as the long form. Although this is a little inconvenient for the printed page, the cuts are made only after each noble gas. There are a number of errors in this table but it was developed before any theory of atomic structure and is, in essence, the modern long version. It needs no modification to include all elements discovered since, and was established solely on the basis of chemical data.

If one compares Werner's table with the modern long form in Fig. 7, the agreement is remarkable. Only a few differences surprise: placing $\mathrm{Be}$ and $\mathrm{Mg}$ above $\mathrm{Zn}$ rather than $\mathrm{Ca}$ is presumably a reflection of the degree of hydrolysis and would not pass the ionization energy and class A or class B tests, both of which lay in the future. 


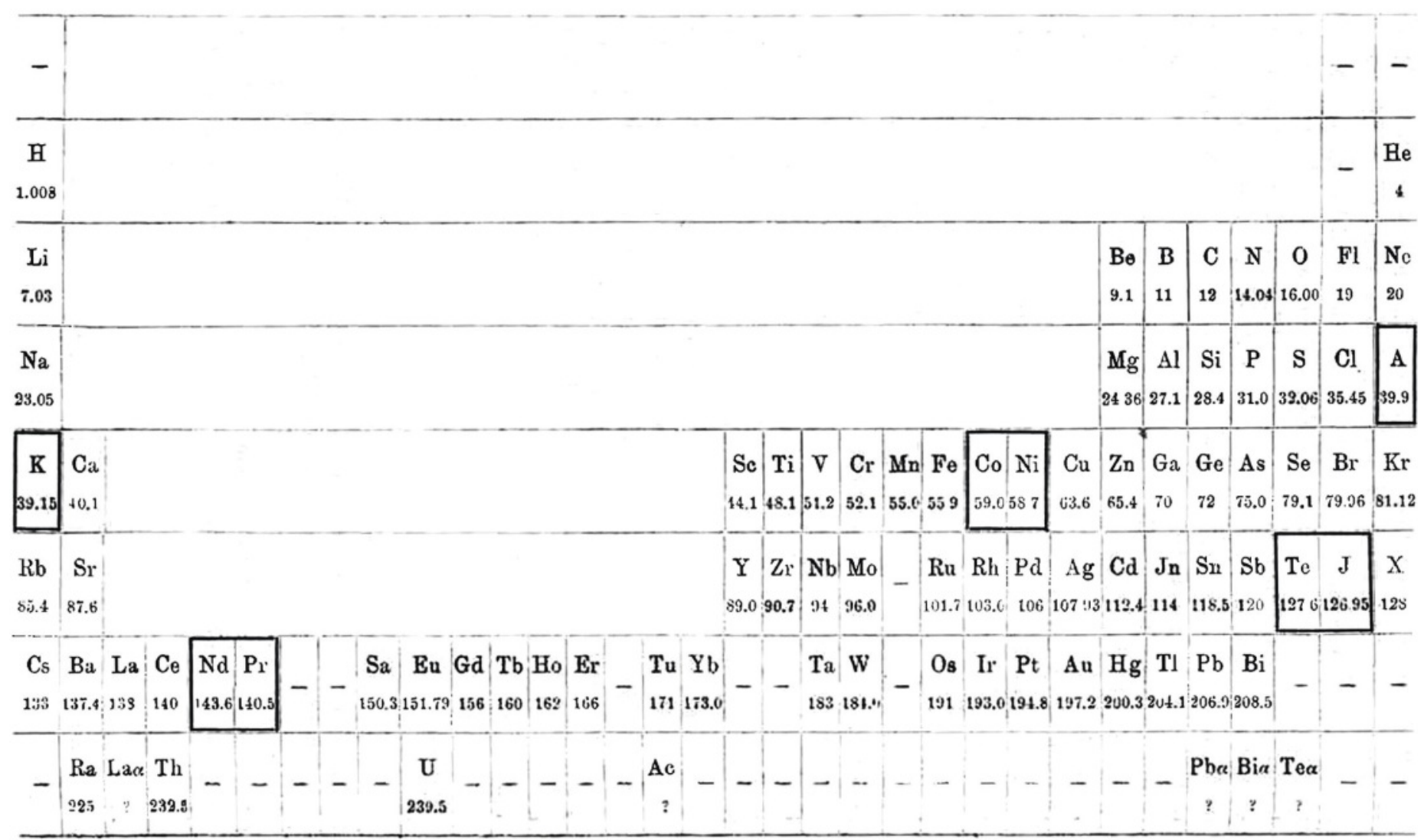

Fig. 6. The periodic table proposed by Alfred Werner in 1905. ${ }^{[17,18]}$ The four pairs of elements surrounded by boxes correspond to cases where the order of increasing atomic weights is not respected. For $\mathrm{Nd}$ and $\mathrm{Pr}$ the entries are simply in the wrong order. There is only one element (Pm) missing before samarium, not two.

\begin{tabular}{|c|c|c|c|c|c|c|c|c|c|c|c|c|c|c|c|c|c|c|c|c|c|c|c|c|c|c|c|c|c|c|c|}
\hline $\mathrm{H}$ & & & & & & & & & & & & & & & & & & & & & & & & & & & & & & & $\mathrm{He}$ \\
\hline Li & $\mathrm{Be}$ & & & & & & & & & & & & & & & & & & & & & & & & & B & C & $\mathrm{N}$ & 0 & $\mathrm{~F}$ & $\mathrm{Ne}$ \\
\hline $\mathrm{Na}$ & $\mathrm{Mg}$ & & & & & & & & & & & & & & & & & & & & & & & & & $\mathrm{Al}$ & $\mathrm{Si}$ & $P$ & $S$ & $\mathrm{Cl}$ & $\mathrm{Ar}$ \\
\hline $\mathrm{K}$ & $\mathrm{Ca}$ & & & & & & & & & & & & & & & Sc & $\mathrm{Ti}$ & V & $\mathrm{Cr}$ & $\mathrm{Mn}$ & $\mathrm{Fe}$ & Co & $\mathrm{Ni}$ & $\mathrm{Cu}$ & $\mathrm{Zn}$ & $\mathrm{Ga}$ & $\mathrm{Ge}$ & As & $\mathrm{Se}$ & $\mathrm{Br}$ & $\mathrm{Kr}$ \\
\hline $\mathrm{Rb}$ & $\mathrm{Sr}$ & & & & & & & & & & & & & & & $Y$ & $\mathrm{Zr}$ & $\mathrm{Nb}$ & Mo & Tc & $\mathrm{Ru}$ & $\mathrm{Rh}$ & $\mathrm{Pd}$ & $\mathrm{Ag}$ & $\mathrm{Cd}$ & In & $\mathrm{Sn}$ & $\mathrm{Sb}$ & Te & 1 & $\mathrm{Xe}$ \\
\hline Cs & $\mathrm{Ba}$ & La & $\mathrm{Ce}$ & $\mathrm{Pr}$ & $\mathrm{Nd}$ & $\mathrm{Pm}$ & $\mathrm{Sm}$ & Eu & Gd & $\mathrm{Tb}$ & Dy & Ho & $\mathrm{Er}$ & $\mathrm{Tm}$ & $\mathrm{Yb}$ & Lu & $\mathrm{Hf}$ & $\mathrm{Ta}$ & W & $\mathrm{Re}$ & Os & Ir & $\mathrm{Pt}$ & $\mathrm{Au}$ & $\mathrm{Hg}$ & TI & $\mathrm{Pb}$ & $\mathrm{Bi}$ & Po & At & $\mathrm{Rn}$ \\
\hline $\mathrm{Fr}$ & $\mathrm{Ra}$ & $A c$ & Th & $\mathrm{Pa}$ & U & $\mathrm{Np}$ & $\mathrm{Pu}$ & $\mathrm{Am}$ & $\mathrm{Cm}$ & $\mathrm{Bk}$ & $\mathrm{Cf}$ & Es & $\mathrm{Fm}$ & $\mathrm{Md}$ & No & $\mathrm{Lr}$ & $\mathrm{Rf}$ & $\mathrm{Db}$ & Sg & $\mathrm{Bh}$ & $\mathrm{Hs}$ & $\mathrm{Mt}$ & Ds & $\mathrm{Rg}$ & $\mathrm{Cn}$ & $\mathrm{Nh}$ & $\mathrm{FI}$ & $\mathrm{Mc}$ & Lv & Ts & Og \\
\hline
\end{tabular}

Fig. 7. The modern long form of the periodic table.

Werner also seemed to think that the gap between hydrogen and helium was too big and suggested a new element, together with three elements even lighter than hydrogen. Others shared such beliefs. Candidates for positions between hydrogen and helium included Mendeleev's 'proto-fluorine'[11] and Rydberg's 'nebulium' and 'coronium' which were associated with unidentified spectral lines in the spectra of stars and the solar corona. These lines later proved to be due to ionized species of existing elements. An interesting discussion of the redundant elements and Werner's table is given by Heilbron. ${ }^{[19]}$ Finally we should note that Werner placed the as yet undiscovered Lu and Lr below Sc and $\mathrm{Y}$, and predicted an actinide series, correctly placing Th below Ce although his judgement was less sure with uranium.

Mendeleyev classified the elements into groups and attributed Roman numerals to them, adding A and B designators later. IUPAC later decided to number with Arabic numerals the groups in the medium length table. Although this of course broke the link between group number and maximum valence, it remains a useful designator for teaching. It seems unlikely that a numbering based on the long form will be adopted since we do not see description of the halogens as group 31 as likely to be popular. It will be noticed that the different versions of the table give different weights to different aspects of the chemistry of the elements. Biochemists and most organic chemists are unlikely to be upset at the placing of the lanthanides and actinides in a footnote but inorganic chemists do not like this.

We have been quite modest in giving only five versions of the table since there are hundreds more representations. ${ }^{[20]}$ Each chemist will no doubt choose that which best suits him, although observation suggests that the medium length table is currently most used for teaching. A IUPAC working group is currently studying the possibility of a definitive version.

\section{Conclusions}

We have tried to show how the notion of the periodic table developed slowly from the ideas of Lavoisier. Mendeleyev's version was the most complete, and his work in advertising it and showing its usefulness, together with the carefully argued predictions of new elements and corrections of previous errors justify the preeminent position accorded him. The table has been able to accommodate the discovery of new elements, the identification of isotopes and the quantum mechanical description of the atom. After 150 years it still classifies all known elements in a satisfactory way. The periodicity observed by the earliest workers 
has been confirmed not only by the elements discovered since then, but also by the great volume of physicochemical data that has now been gathered such as ionization energies and heats of atomization. Although physics has made great contribution to our understanding, it is to be noted that the structure of the periodic table, up to and including the actinides, was based on chemical observation. The periodic table thus stands as one of chemistry's major achievements.

All the gaps in Mendeleyev's table are now filled, and the prediction of new elements will henceforth be a question for nuclear physicists, but this does not diminish in any way the importance of the periodic table. It remains a remarkable tool for organizing chemical knowledge. In education it is one of the most efficient aide-memoires ever produced, and it is remarkably successful in helping students to assimilate the properties of over 100 different elements and identifying trends. ${ }^{[21]}$ What was a construction based purely on observation has proven perfectly adaptable to chemical bonding theory. The periodic table also plays a role in guiding chemical thought and in stimulating the creative faculties of synthetic chemistry.

We may also ask what is the best medium to present the periodic table. Most readers will be familiar with the chart on the wall of a classroom or lecture theatre, but at a time where students will consult more readily a tablet or smartphone, the days of the chart may be numbered. Sir Martyn Poliakoff has developed a series of short video presentations based on the periodic table ${ }^{[22]}$ which may readily be consulted and which, by the elegant demonstrations that they feature, combine modern media with the showmanship so popular in scientific lectures of the nineteenth century.

The periodic table is arguably the backbone of modern chemistry, but it does not represent a mathematical progression across periods and down groups. Mendeleyev was caught out when he estimated the melting point of gallium to lie between aluminium and indium, when it is much lower than either. Similarly the $4 \mathrm{~d}$ elements are much closer to the $5 \mathrm{~d}$ in chemical behavior than the $3 \mathrm{~d}$. Elements from quite different parts of the periodic table can sometimes show very similar behavior under certain conditions: $\mathrm{Fe}^{3+}$ can substitute for $\mathrm{Al}^{3+}$ in clay minerals, simply because they coincidentally have equal charge and very similar size. This may seem disappointing, but provided we keep our critical senses awake the periodic table is a reliable guide; if everything was completely predictable would chemistry be any more interesting?
[1] J. Emsley, 'Nature's Building Blocks', 2nd ed., Oxford University Press, Oxford, 2011.

[2] F. A. Cotton, R. A. Walton, 'Multiple Bonds between Metal Atoms', Oxford University Press, Oxford, 1993.

[3] D. M. P. Mingos, Chimia 2019, 73, 152.

[4] E. Scerri, 'The Periodic Table. Its Story and Its Significance', Oxford University Press, Oxford, 2007.

[5] E. Scerri, Phil. Trans. R. Soc. A 2015, 373.

[6] IUPAC, https://iupac.org/what-we-do/periodic-table-of-elements/.

[7] S. Cannizzaro, Nuovo Cimento 1858, 7, 321 .

[8] A. F. Williams, Chimia 2009, 63, 839.

[9] Williams Haynes Portrait Collection, Science History Institute, Philadelphia, https://digital.sciencehistory.org/works/6682 $\times 411 q$.

[10] J. M. Thomas, Angew. Chem. Int. Ed. 2004, 43, 6418.

[11] D. I. Mendeleyev, in 'Principles of Chemistry', 3rd English Ed., Longmans, London, 1905, Vol. 1, pp. xviii; Vol. 2, pp. 509-529.

[12] N. Bohr, Phil. Mag. 1913, 25, 1; N. Bohr, Phil. Mag. 1913, 25, 476; N. Bohr, Phil. Mag. 1913, 25, 857.

[13] N. Bohr, Nature 1923, 112, 29.

[14] G. Seaborg, 'Man-made Transuranium Elements', Prentice Hall, Englewood Cliffs, New Jersey, 1963.

[15] J. Thomsen, Z. Anorg. Chem. 1895, 9, 190

[16] T. K. Sato, M. Asai, A. Borschevsky, R. Beerwerth, Y. Kaneya, H. Makii, A. Mitsukai, Y. Nagame, A. Osa, A. Toyoshima, K. Tsukada, M. Sakama, S. Takeda, K. Ooe, D. Sato, Y. Shigekawa, S.-i. Ichikawa, C. E. Düllmann, J. Grund, D. Renisch, J. V. Kratz, M. Schädel, E. Eliav, U. Kaldor, S. Fritzsche, T. Stora, J. Am. Chem. Soc. 2018, 140, 14609.

[17] A. Werner, Chem. Ber. 1905, 38, 914.

[18] A. Werner, 'Neuere Anschauungen auf dem Gebiete des Anorganischen Chemie', Braunschweig, 1905.

[19] J. L. Heilbron, in 'H.G.J. Moseley; The Life and Letters of an English Physicist', University of California Press, 1974, pp. 90-94.

[20] J. H. van Spronsen, 'The Periodic System of the Chemical Elements', Elsevier, Amsterdam, 1969.

[21] D. M. P. Mingos, 'Essential Trends in Inorganic Chemistry', Oxford University Press, Oxford, New York, Tokyo, 1998.

[22] M. Poliakoff, http://www.periodicvideos.comm/. 